\title{
The Analysis of Tautology in Political Discourse
}

\author{
Yan Niu* \\ School of Marxism, Northwest Normal University, Lanzhou 730050, China \\ *Corresponding author. Email: nyhh919@sohu.com
}

\begin{abstract}
This paper discusses one intriguing but complicated issue about identity in tautological constructions in Chinese political discourse. We recognized that, though Russell's description theory is helpful to exploit the logical mechanism underlying the grammatical forms, it still has the difficulties in describing the relationship between logic and language experience. That's why we talked about Grice's theoretical contributions. And finally, we find an ideal theory to describe the relationship between them.
\end{abstract}

Keyword: Identity, Numerical identity, Qualitative identity, Tautological constructions, Mandarin.

\section{INTRODUCTION}

In philosophy, "identity" is defined as: (i) sameness of essential or generic character in different instances; or (ii) sameness in all that constitutes the objective reality of a thing. However, a further distinction drawn between (i) and (ii) indicates that the concept of identity is more complicated than intriguing in ordinary language interpretation. Definition (i), termed as qualitative identity which denotes that different things share certain common properties, is logically expressed as " $\mathrm{a}=\mathrm{b}$ "; while definition (ii), known as numerical identity, requires absolute, or total, qualitative identity, and can only hold between a thing and itself, which is presented as a logical form of " $\mathrm{a}=\mathrm{a}$ " (Hall, 1933). It is conceded by most philosophers of language, even recently by some linguistics, that the interpretation of the identity is helpful to solve certain technical problems of logic (Russell, 1905; Wishon, 2017). But we still have some difficulties in understanding certain sentence patterns like tautology in every-day language.

In Mandarin, a pervasively spreading tautological construction, known as "X (adv) SHI X", is widely spoken in our daily communication (Gao, 2010). " $X$ (adv) SHI X" means " $\mathrm{X}$ is $\mathrm{X}$ ". A concrete example is shown below:

(1) Makesi (adv) jiu shi makesi

Marx adv. (emphatic) is Marx.

Marx is Marx.

Obviously, there is something odd in (1) about identity. On the one hand, we appear to use the concept of numerical identity to decode (1). Namely, it is a simple tautology of " $X$ is $X$ " or " $a=a$ " in the form and conveys nothing new in the meaning to the addressee. On the other hand, (1) reflects that it is not a simple repetition of the topic word but an instantiation of qualitative identity to implicate something new like the doctor is competent, which functions as " $\mathrm{a}=\mathrm{b}$ ". We cannot be certain that how we could decode the tautology constructions like (1) more properly, accurately and meaningfully. For these reasons, thus, we recognize that the interpretation of such construction seems to be a matter of considerable difficult: indeed, it is very hard to frame any theory only confine itself to the domain of formalism. All the difficulties with which I am acquainted are met, so far as I can discover, by the theory I am about to explain.

The subject of interpreting the identity in Mandarin tautology construction is of very importance, not only in logic, but also in theory of linguistics, particular in semantics and pragmatics. The course of my argument will be as follow. I shall begin by stating what typical Mandarin tautology construction is; I shall then discuss the theories of Russell, Grice and Fillmore, showing the strengths and weaknesses of all the theories; then I shall give the grounds in favor of my own stance; and finally I shall briefly indicate the linguistics consequence of the cognitive perspective

\section{DETAILED ANALYSIS}

According to Russell (1905), the grammatical forms, the denoting phrases for instance, are not assumed to have meaning in isolation, but that every proposition in 
which they occur has a meaning. That is, meaning is developing from proposition rather than from the grammatical form. Thus, the difficulties concerning denoting are all the result of a wrong analysis of propositions whose verbal expressions or grammatical forms contain denoting phrases. In logical discourse, we cannot use the same term in the same discourse while having it signify different senses or meanings - even though the different meanings are conventionally prescribed to that term, which the ancient Greeks called its essence. For example, the qualitative identity in the grammatical form "The author of Waverley was Scott" can be explicitly illustrated in logical symbolic in (2).

(2) $\exists x(F x \wedge \forall y(F y \rightarrow y=x)$

"Fx": x wrote Waverley; "Fy": y wrote Waverley below:

The logical form of (2) could be interpreted as

(i) There is an individual $\mathrm{x}$; (ii) $\mathrm{x}$ wrote Waverley: $\mathrm{Fx}$; (iii) there is no individual $\mathrm{y}$ besides $\mathrm{x}$ that has the property of the author of Waverley: $\forall \mathrm{y}(\mathrm{Fy} \rightarrow \mathrm{y}=\mathrm{x})$; (iv) $\mathrm{x}$ is Scott.

If we adopt a grammatical form analysis to the sentence in (3), we would be baffled by a misleading result with numerical identity property.

(3) George IV wished to know whether Scott was the author of Waverley.

If in fact, Scott was the author of Waverley, we may substitute "Scott" for "the author of Waverley". And then we get (4).

(4) George IV wished to know whether Scott was Scott.

We can, therefore, reconfirm that the logical symbolic could successfully avoid the misleading interpretation of numerical identity and could properly analyze the essence of the meaning of the grammatical form with the property of qualitative identity.

In a stark contrast, the current topic in this paper is to treat a kind of construction with the property of numerical identity in surface structure. How could we interpret the tautological constructions like (5)?

(5) boshi shi boshi.

doctor is doctor.

The doctor is a doctor.

Logically, a valid inference of the proposition of "boshi shi boshi" (doctor is doctor) appears to be presented as the following to possibilities:

(i) there exists a doctor $\mathrm{x}$; $\mathrm{x}$ belongs to set $\mathrm{A}: \mathrm{x} \in A$; For any $\mathrm{y}$, it belongs to set $\mathrm{B}: \forall \mathrm{y}(\mathrm{y} \in \mathrm{B})$; If and only if $\mathrm{x}$ belongs to set $C$, the intersection of set $A$ and set $B$, and set $\mathrm{C}$ equals t4o the union of set $\mathrm{A}$ and set $\mathrm{B}$, $\mathrm{x}$ equals to $\mathrm{y}: \forall \mathrm{x}(\mathrm{x} \in \mathrm{C}) \wedge \mathrm{C} \vDash((\mathrm{A} \cap \mathrm{B})=(\mathrm{A} \cup \mathrm{B})) ; \mathrm{x}$ equals to $\mathrm{y}:$ $\mathrm{x}=\mathrm{y}$.

This type of tautology could be interpreted as (6).

(6) $\exists x(\forall x(x \in A) \wedge \forall y(y \in B) \wedge \forall x(x \in C) \wedge C \vDash$ $((A \cap B)=(A \cup B)) \rightarrow x=y)$

(ii) there exists a doctor $\mathrm{x}$; $\mathrm{x}$ belongs to set $\mathrm{A}: \mathrm{x} \in A$; For any $\mathrm{y}$, it belongs to set $\mathrm{B}: \forall \mathrm{y}(\mathrm{y} \in \mathrm{B})$; If and only if $\mathrm{x}$ belongs to set $\mathrm{C}$, the intersection of $\mathrm{A}$ and $\mathrm{B}$, and set $\mathrm{C}$ is not equivalent to the union of set $\mathrm{A}$ and set $\mathrm{B}$ : $\forall \mathrm{x}(\mathrm{x} \in \mathrm{C}) \wedge \mathrm{C} \vDash(\mathrm{A} \cap \mathrm{B}) \wedge \mathrm{C} \vDash \sim(\mathrm{A} \cup \mathrm{B}) ; \mathrm{x}$ equals to $\mathrm{y}$ : $\mathrm{x}=\mathrm{y}$.

This type of tautology could be interpreted as (7).

(7) $\exists \mathrm{x}(\forall \mathrm{x}(\mathrm{xA}) \wedge \forall \mathrm{y}(\mathrm{yB}) \wedge \forall \mathrm{x}(\mathrm{xC}) \wedge \mathrm{C} \vDash(\mathrm{A} \cap \mathrm{B}) \wedge$ $\mathrm{C} \vDash \sim(\mathrm{A} \cup \mathrm{B}) \rightarrow \mathrm{x}=\mathrm{y})$

The tautology represented in (6) is numerical identity and that in (7) is qualitative one. However, during the course of natural language processing, how could we choose a valid inference more properly between different types of identities? Context is assumed to be helpful in the interpretation of the logical ambiguities underlying the grammatical forms in the natural language. To be more specific, the contexts, transparent or opaque, may offer more information about the time, space and participants et al. which would be considered as the key elements to determine the truth-value of a proposition (Burgess, 2018). Logic may be aided and intelligible in the interpretation of the grammatical forms but the grammatical forms' interpretation cannot be totally supplanted by the logical one. As the ordinary language is too complicated, the logical interpretation is only part of story in language processing (Grice, 1975). To have a panorama of the essence of the meaning of a proposition, we are required to shed light to the relationship between meaning and context (Grice, 1957).

\section{MEANING AND CONTEXT}

According to Grice (1957), the meaning of certain proposition in a context would be classified into natural meaning and non-natural meaning. For instance, in the following two sentences, the word "mean" in (10) represents a natural correlation between the spots and the measles, whereas the word "mean" in (11) does not indicate any natural connection between the three rings and the bus's being full.

(8) Those spots mean (meant) measles.

(9) Those three rings on the bell (of the bus) meant that the bus was full.

The natural meaning is factive, evidential, non-accidental, and non-voluntary (devoid of human intention), which could not be changed by any human being. That is, the meaning is not related to human 
communication. The non-natural meaning, by contrast, is non-factive, intentional, voluntary, which appears to involve human intentions. For instance, it is a particular human being (e.g., the bus conductor) that intends the three rings to mean that the bus is full. It is possible for some other people to intend that only one ring to signal the bus is full. Therefore, the non-natural meaning would be constrained by the social convention. Only those socially conventionalized meaning could be accepted by the langue community. Otherwise, any non-entrenched meaning would not survive.

As Grice (1975) contended, to achieve a full identification of the meaning conveyed in an utterance, some contextual information is required - certainly enough to resolve ambiguities and secure reference for the indexicals. An intriguing fact recognized by Grice (1975) is that for any specific intentionality, the speakers are more likely to adopt different maxims, for instance, quantity, quality, relation, and manner, to realized different communication purposes. Any violation of the maxims would be assumed as to indicate a particular implicature. In consequence, if the non-natural meaning is activated in the addressees' mind, the difficulties of finding which logical alternations would be solved.

The Gricean pragmatic analysis tells that the non-natural meaning of the tautological constructions is context-depended. That is, the connotation of tautological constructions in Mandarin would be activated by different context information. Within the frame of a certain context, we may switch to a certain type of identity analysis, and then the corresponding pragmatic connotations would be activated. We might think that the Gricean pragmatic analysis is an ideal theoretical approach to give another stroke in the diagram of decoding the mechanism of tautological constructions in Chinese political discourse.

\section{A MORE COMPLICATED SITUATION}

After talking about the prototypical tautology in Mandarin, we would like to discuss a more complicated one like (10).

(10) Ta bi makesi hai makesi.

He comparative marker Marx even more Marx

He knows more about Marxism than Marx himself.

In construction "Y BI (comparative marker) X HAI (adv. even more) X", the comparative marker "BI" and the adverb "HAI" would tell us that we would compare a certain entity with another one within a certain domain in terms of common properties. That is, there exist certain commonalities between the two entities mentioned in the construction. In (10), there is no extra background information is supplied. Therefore, the maximality value would be realized on the basis of the pattern "Y BI (comparative marker) X HAI (adv. even more) $X$ " itself. However, all the motivating context would lead us to switch to the qualitative identity. The (10) could be interpreted as below:

(i). There exists an entity $\mathrm{x}$; (ii). For any $\mathrm{x}$, it belongs to set $\mathrm{A}$ : $\mathrm{x} \in \mathrm{A}$; (iii). For anyone called Marx, here represented as $\mathrm{y}$, it belongs to set $\mathrm{B}: \forall \mathrm{y}(\mathrm{y} \in \mathrm{B})$; (iv). If and only if $x$ belongs to set $C$, which is the intersection of $\mathrm{A}$ and $\mathrm{B}$, and set $\mathrm{C}$ is not equivalent to the union of set $\mathrm{A}$ and set $\mathrm{B}: \forall \mathrm{x}(\mathrm{x} \in \mathrm{C}) \wedge \mathrm{C} \vDash(\mathrm{A} \cap \mathrm{B}) \wedge$ $\mathrm{C} \vDash \sim(A \cup B) ;(v)$. $x$ is even more than $y: x>y$.

This type of tautology could be interpreted as (11).

(11) $\exists \mathrm{x}(\forall \mathrm{x}(\mathrm{x} \in \mathrm{A}) \wedge \forall \mathrm{y}(\mathrm{y} \in \mathrm{B}) \wedge \forall \mathrm{x}(\mathrm{x} \in \mathrm{C}) \wedge \mathrm{C} \vDash(\mathrm{A} \cap \mathrm{B})$ $\wedge \mathrm{C} \vDash \sim(\mathrm{AUB})) \rightarrow \mathrm{x}>\mathrm{y})$

Thus, at the macro-level, we can decide the identity type to look into the logical structure of the proposition; at the micro-level, we could avoid the ambiguities from the grammatical structure.

\section{CONCLUSION}

Based on the above assumptions, we conclude that the description of meaning-bearing elements in the language must consider the essence of the logic.

\section{REFERENCES}

[1] Burgess, A. The Things We Do with Identity. Mind, 127(505) (2018) 105-128.

[2] Gao, H. A Construction Grammar Analysis of Tautologies. Journal of Pla University of Foreign Languages, 33(5) (2010) 6-127.

[3] Grice, H. P. Meaning. Philosophical Review, 66(3) (1957) 377-388.

[4] Grice, H. P. Logic and conversation. In P. Cole \& J. L. Morgan (Eds.), Syntax and semantics 3: Speech arts, New York, Academic Press, 1975, pp. 41-58.

[5] Hall, E. W. Numerical and Qualitative Identity. The Monist, 43(3) (1933) 88- 104.

[6] Russell, B. On Denoting. Mind, 14(56) (1905) 479-493.

[7] Wishon, D. Russellian Acquaintance and Frege's Puzzle. Mind, 126(502) (2017) 321-370. 